\title{
Formulating for Innovative Self-Compacting Concrete with Low Energy Super-Sulfated Cement Used for Sustainability Development
}

\author{
Hoang-Anh Nguyen ${ }^{1,2}$, Ta-Peng Chang ${ }^{1}$, Jeng-Ywan Shih ${ }^{3}$, Chun-Tao Chen ${ }^{2}$ \\ ${ }^{1}$ Department of Civil and Construction Engineering, National Taiwan University of Science and Technology \\ (NTUST) (Taiwan Tech), Taiwan \\ ${ }^{2}$ Department of Civil Engineering, College of Engineering Technology, Cantho University, Cantho City, Vietnam \\ ${ }^{3}$ Department of Chemical Engineering, Ming Chi University of Technology, Taiwan \\ Email: hoanganh@ctu.edu.vn, "tpchang@mail.ntust.edu.tw, jengywan@gmail.com, \\ chuntaoc@mail.ntust.edu.tw
}

Received 12 March 2016; accepted 21 July 2016; published 25 July 2016

\section{Abstract}

This study proposed a new way to formulate a low energy super-sulfated cement (SSC) which can be used to produce self-compacting concrete (SCC) with high compressive strength and durability in terms of chloride penetration resistance. This innovative SSC, different from the traditional SSC, was purely produced with a ternary mixture of three industrial by-products of ground granulated blast furnace slag, low calcium Class F fly ash and circulating fluidized bed combustion (CFBC) fly ash and was denoted as SFC-SSC (super-sulfated cement made by mixture of slag, Class F fly ash and CFBC fly ash). Experimental results showed that the combination of a fixed amount of $15 \mathrm{wt} . \%$ of CFBC fly ash with various ratios of Class F fly ash to slag could be used to produce the hardened SCCs with high 28-day compressive strengths (41.8 - 65.6 MPa). Addition of Class F fly ash led to the resulting SCCs with lowered price and preferable engineering properties, and thus it was considered as state-of-the-art method to drive such type of concrete towards sustainable construction materials.

\section{Keywords}

CFBC Fly Ash, Fly Ash, Slag, Super-Sulfated Cement, High-Strength Self Compacting Concrete

\section{Introduction}

Super-sulfated cement (SSC), which is fabricated mostly without OPC, has been the research interest because of its low heat of hydration and superior resistance to chemical attacks [1]. In the past decades, the SSC has been commonly used as one of commercial cements in Europe and India because when compared with the OPC manufacture, its manufacture is the simple, little consumption of natural material and energy and low carbon dioxide

\footnotetext{
${ }^{*}$ Corresponding author.
}

How to cite this paper: Nguyen, H.-A., Chang, T.-P., Shih, J.-Y. and Chen, C.-T. (2016) Formulating for Innovative Self-Compacting Concrete with Low Energy Super-Sulfated Cement Used for Sustainability Development. Journal of Materials Science and Chemical Engineering, 4, 22-28. http://dx.doi.org/10.4236/msce.2016.47004 
emissions [2]-[5]. Normally, the mixture of $80 \%$ - 85\% ground granulated blast furnace slag, $10 \%$ - 15\% sulfate activator (anhydrite or gypsum) and low amount of OPC (normally 5\%) has been widely used for fabricating SSCs [2] [5]. For SSCs, because the glassy phases in slag are mostly monosilicates similar to those in Portland cement clinker, the slag particles will easily dissolve in low to mild alkaline solution and thus it plays a primary role as the main powder [6]. However, the slag with large surface area and sharp particles cause the poor workability of the SSCs. Moreover, the cost of the SSCs is high due to the limited quantity of raw materials, such as slag required to include high alumina [1] [7]. To lower the cost of the SSC, the circulating fluidized bed combustion (CFBC) fly ash has been used as activator instead of mixture of gypsum and OPC/hydrated lime used in traditional SSC [8] [9]. Similar to the conventional SSC, the SSCs triggered by CFBC fly ash also face the poor workability and the high cost because of high amount of slag. To reduce the cost of the SSC, the utilization of slag/fly ash blending powder triggered by flue gas desulfurization (FGD) gypsum was proposed [10] [11]. However, the negative effect of fly ash additive on the compressive strength of cement was also observed [10]. Therefore, the challenge of fabricating the SSCs with reduced cost and increased mechanical property is always the goal to pursue better SSCs with $100 \%$ by-product wastes. This study proposes a new way to produce highstrength self-compacting concrete (SCC) with an innovative low energy SSC, which, different from the aforementioned SSC, is purely composed of a ternary mixture of three industrial solid by-products of ground granulated blast furnace slag (S), low calcium Class F fly ash (F) and circulating fluidized bed combustion (CFBC) fly ash (C) [12]. The addition of Class F fly ash in SFC-SSC (super-sulfated cement produced by mixture of slag, Class F fly ash and CFBC fly ash) is to improve both workability and mechanical properties of high-strength SFC-SSC concrete. According to the resulting mechanical and durability behaviors, the SFC-SSC concrete in this investigation challenges the conventional SCC concretes by eliminating the cost of OPC and reducing environmental impacts. This SFC-SSC concrete, therefore, is an important choice for the development of sustainability, as pointed out by Damtoft et al. [13].

\section{Experimental Program}

\subsection{Materials and Mix Proportions of SFC-SSC Concrete}

The commercial Type I Portland cement in accordance to ASTM C150 was used as the reference binder. Mixture of Class F fly ash (FFA), ground granulated blast furnace slag (GGBFS) and CFBC fly ash (CFA) were used to produce the SFC-SSC. The chemical and mineral compositions of raw materials were shown in Table $\mathbf{1}$ and Figure 1, respectively. Crushed natural stone with maximum size of $20 \mathrm{~mm}$ and river sand with fineness modulus (FM) of 2.9 were used as coarse and fine aggregates, respectively. The specific gravities of sand and crushed stone are 2.65 and 2.67, and water absorptions are $0.8 \%$ and $1.0 \%$, respectively. Both sand and crushed stone were carefully washed to ensure good binding in concrete mixtures.

Table 1. Physical properties and chemical compositions of three industrial solid by-products.

\begin{tabular}{cccc}
\hline & GGBFS & FFA & CFA \\
\hline Specific gravity & 2.90 & 2.08 & 2.70 \\
Blaine fineness, $\mathrm{cm}^{2} / \mathrm{g}$ & 6000.00 & - & 3000.00 \\
$\mathrm{SiO}_{2}$, wt.\% & 34.90 & 61.12 & 5.22 \\
$\mathrm{Al}_{2} \mathrm{O}_{3}$, wt.\% & 13.53 & 24.31 & 2.21 \\
$\mathrm{Fe}_{2} \mathrm{O}_{3}$, wt.\% & 0.52 & 4.26 & 0.58 \\
$\mathrm{CaO}$, wt.\% & 41.47 & 4.65 & 56.80 \\
$\mathrm{MgO}$, wt.\% & 7.18 & 1.15 & 2.06 \\
$\mathrm{SO}$, wt.\% & 1.74 & - & 32.40 \\
$\mathrm{~K}_{2} \mathrm{O}$, wt.\% & - & 0.33 & - \\
$\mathrm{TiO}_{2}$, wt.\% & - & 1.48 & - \\
L.O.I, wt.\% & 4.72 & 2.70 & - \\
\hline
\end{tabular}

GGBFS: ground granulated blast furnace slag; FFA: Class F fly ash; CFA: circulating fluidized bed combustion (CFBC) fly ash. 
In this study, the CFA with a fixed 15 wt.\% of the combined mixture of FFA and GGBFS was used to trigger the hydration of SFC-SSC [14]. Five values of 0, 10, 20, 30 and 50 wt.\% of FFA, as partial replacement for GGBFS by $0,10,20,30$ and 50 wt.\%, were used to produce SFC-SSC. Flowable plain OPC concrete was cast for comparison. In addition, the concrete specimen using slag-CFA binder with an optimum mixture of 80 wt.\% GGBFS and 20 wt.\% CFA, as suggested by Dung, Chang [8], was also produced for comparison. The water to binder ratio (W/B) of SFC-SSC concrete was fixed at 0.3 . The volume of paste and weight ratio of sand to mixture of sand and stone were fixed at $37.05 \%$ and 0.55 , respectively. To control the workability of fresh concretes, Type G superplasticizer (SP) was used. The mix proportions of SFC-SSC concretes are shown in Table 2, where in the mixture designation, the characters $\mathrm{F}$ and $\mathrm{C}$ refer to the Class F fly ash (FFA) and CFBC fly ash (CFA), respectively. The numbers immediately following the characters represent the weight percentage of the materials used in the no-cement SFC binder.

\subsection{Specimen Preparation and Test Methods}

The property of fresh SFC-SSC concrete was adjusted in accordance with consistency and unconfined flow

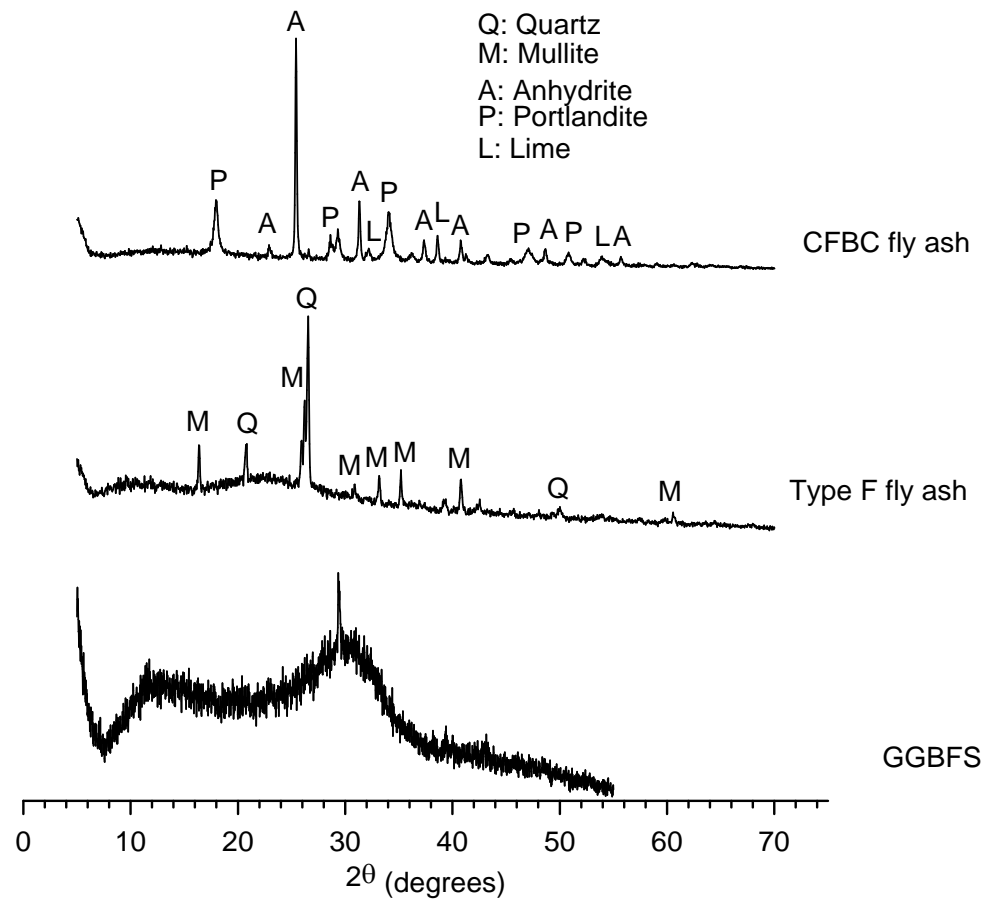

Figure 1. XRD patterns of three industrial solid by-products.

Table 2. Mix proportions for self-compacting concrete (SFC-SSC concrete).

\begin{tabular}{ccccccccc}
\hline Mixture Destination & OPC & Slag & FFA & CFA & Water & Sand & Stone & SP \\
\hline OPC & 600 & - & - & - & 180 & 921 & 753 & 3.00 \\
F00C25 & - & 456 & - & 114 & 171 & 921 & 753 & 2.00 \\
F00C15 & - & 497 & - & 75 & 171 & 921 & 753 & 2.00 \\
F10C15 & - & 439 & 49 & 73 & 168 & 921 & 753 & 1.97 \\
F20C15 & - & 384 & 96 & 72 & 165 & 921 & 753 & 1.93 \\
F30C15 & - & 330 & 141 & 71 & 163 & 921 & 753 & 1.90 \\
F50C15 & - & 228 & 228 & 68 & 157 & 921 & 753 & 1.83 \\
\hline
\end{tabular}

OPC: Ordinary Portland Cement; SP: Type G superplasticizer. 
potential as suggested by ASTM C1611 and passing ability by J-Ring proposed by ASTM C1621. The cylindrical specimens of SFC-SSC concretes with diameter of $100 \mathrm{~mm}$ and length of $200 \mathrm{~mm}$ were cast for the tests of compressive strength in accordance to ASTM C39 and rapid chloride penetration test (RCPT) in accordance to ASTM C1202. After 24 hours of curing in the molds at room temperature of $27^{\circ} \mathrm{C} \pm 2^{\circ} \mathrm{C}$, all specimens were removed and cured in the room temperature of $27^{\circ} \mathrm{C} \pm 2^{\circ} \mathrm{C}$ and $65 \% \mathrm{RH}$. To interpret the effect of mix proportion on the cost of the SFC-SSC concrete, the strength efficiency (SE) of concretes was calculated. The formula of the SE for the SFC-SSC concrete is assumed to be described as:

$$
S E=\frac{f_{c}^{\prime}}{E_{s}}\left(\text { unit }: \frac{\mathrm{MPa}}{\mathrm{kg} / \mathrm{m}^{3}}\right)
$$

where $S E, f_{c}^{\prime}$, and $W_{s}$ are the strength efficiency of SFC-SSC concretes, compressive strengths of concretes at testing time, and weight of GGBFS in a cubic mix proportion of concrete, respectively. Because the cost of GGBFS is higher than that of FFA or CFA, the decrease of cost of the SFC-SSC was associated with the increase of SE.

\section{Results and Discussion}

\subsection{Workability}

The fresh properties of the resulting SFC-SSC concretes are summarized in Table $\mathbf{3}$ and visually described in Figure 2. Table 3 shows that most of the SFC-SSC concretes illustrated the slump flow in range of 60 - $65 \mathrm{~cm}$, as normally suggested for SCC manufacture. The increased FFA additive led to the increased flowability as demonstrated by the reducing amount of SP used. The visual stability index (VSI) values of the SFC-SSC concretes, based on ASTM C1611, were from 0 to 1 implies the accepted stability of the SFC-SSC concretes due to no segregation and bleeding (Figure 2). In this study, the SFC-SSC concretes with FFA additive had the excellent passing ability due to minor difference between slump flow and J-Ring flow (lower than $25 \mathrm{~mm}$ ), which referred to no visible blocking. However, the SFC-SSC concretes without FFA additive had noticeable blocking during flowing because the difference between slump flow and J-Ring was beyond $25 \mathrm{~mm}$. The increased CFA did not improve the fresh properties of the SFC-SSC concretes without FFA but slightly reduced flowing and passing ability because of the irregular shapes of CFA and increased water demand during the reaction of f-CaO. On the other hand, the flowing and passing ability of the OPC concrete was poor due to the poorly optimized and irregular shapes of OPC particles and more demand of water for certain workability due to water loss caused by flocs.

\subsection{Compressive Strength}

The compressive strengths of SFC-SSC concretes are shown in Figure 3. The compressive strengths of the concretes specimens increased with the increased curing ages. The early compressive strengths (at 7 days) of the SFC-SSC concretes were improved with the increased FFA from 0 to 10 wt.\% due to the accelerating the reaction between GGBFS and CFA at early ages by the nucleation and dilution effects of FFA [15]. However,

Table 3. Fresh properties of SFC-SSC concretes.

\begin{tabular}{cccc}
\hline Mixture Destination & Slump flow mm & J-Ring $\mathrm{mm}$ & Unit weight $\mathrm{kg} / \mathrm{m}^{3}$ \\
\hline OPC & 500 & 400 & 2459 \\
F00C25 & 600 & 540 & 2436 \\
F00C15 & 630 & 570 & 2456 \\
F10C15 & 640 & 620 & 2446 \\
F20C15 & 640 & 620 & 2441 \\
F30C15 & 650 & 630 & 2399 \\
F50C15 & 650 & 630 & 2371 \\
\hline
\end{tabular}




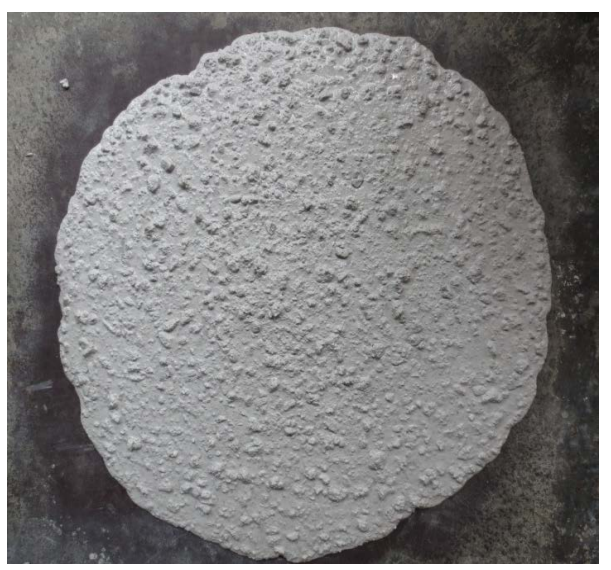

(a)

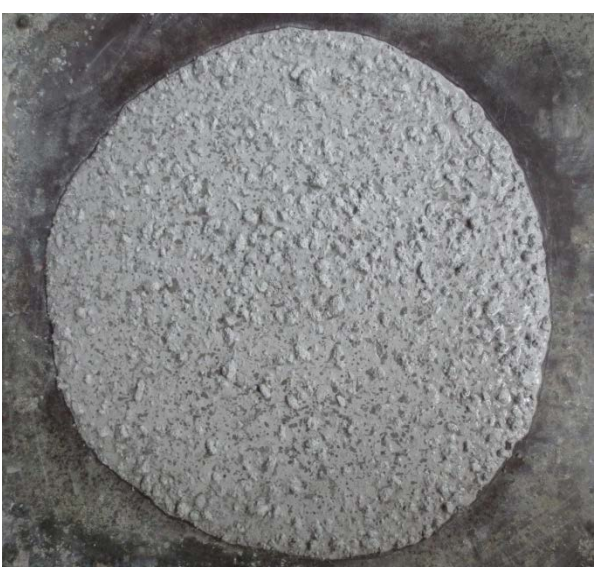

(b)

Figure 2. Workability of the SFC-SSC concretes with (a) no FFA additive and (b) with FFA replacing for GGBFS. (a) SFC-SSC concrete without FFA; (b) SFC-SSC concrete with FFA.

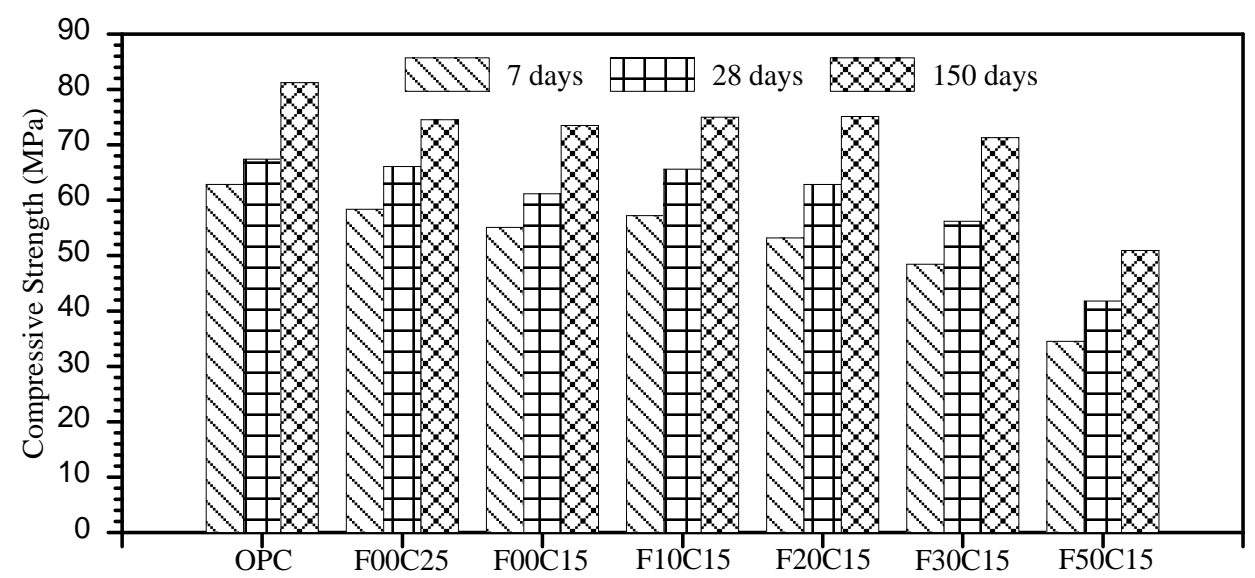

Figure 3. Compressive strengths of SFC-SSC concrete with different mix proportions.

Figure 3 shows that beyond 10 wt.\% of FFA led to reduce in early compressive strength of the SFC-SSC concretes, particularly with $50 \mathrm{wt} \%$ of FFA addition. In this study, however, the compressive strengths of the SFC-SSC concretes with up to 50 wt.\% FFA to replace GGBFS were higher than $41 \mathrm{MPa}$ at age of 28 days implies that SFC-SSC concretes were rated as the high-strength concrete [16]. In comparison with the reference mix with 80 wt.\% GGBFS and 20 wt.\% CFA (F00C25), the SFC-SSC concrete with lower CFA but without FFA (F00C15) had lower compressive strength due to lower hydration of GGBFS (Figure 3). By incorporating FFA in a range of $10-20 \mathrm{wt} . \%$ as partial replacement for GGBFS, the optimized particles and improved chemical composition of the SFC-SSC concrete were observed, leading to the improved compressive strengths at all ages [12]. On the other hand, most of the SFC-SSC concretes had compressive strengths lower than OPC concretes at early ages (7 days) because of the slow dissolution of the CFA [17] [18]. However, as the curing age increased up to 28 days, the SFC-SSC concrete with $10 \mathrm{wt} \%$ FFA additive (F10C15 mix) had compressive strength comparable with the OPC concrete (97.3\%). The compressive strength of the SFC-SSC concrete with 20 wt.\% FFA (F20C15) also reached 93.2\% of that of the OPC concrete.

\subsection{Strength Efficiency (SE) of Slag}

In this study, the strength efficiency (SE) of high-cost slag should be calculated with the purpose of estimating the effect of FFA addition on the cost of concrete. The SE of the SFC-SSC concretes is shown in Figure 4. Accordingly, the increased CFA from 15 to 25 wt.\% increased the SE of the SFC-SSC concrete, leading to the lowered cost of the concrete manufacture. However, Figure 4 shows that the SE of SFC-SSC concrete containing 
lower amount of CFA was significantly improved as the GGBFS was replaced by FFA additive. In this study, the increased FFA additive up to 50 wt.\% resulted in significant increase of SE for the SFC-SSC concrete at all ages. Therefore, FFA addition is highly encouraging to use FFA for producing the SFC-SSC concrete with reduced cost.

\subsection{Chloride Penetration Resistance}

The rapid chloride penetration test (RCPT) was conducted at age of 28 days and the results are shown in Figure 5. According to the figure, the SFC-SSC concretes regardless of CFA and FFA amounts illustrated good resistances to the chloride penetration because of the very low charge passed (100 - 1000 coulombs). The increased CFA increased the charge passed due to the less condensed microstructure. The increased FFA additive up to 30 wt.\% (especially $20 \mathrm{wt} . \%$ ) significantly reduced the charge passed because of the improved microstructures of specimens. However, the increased FFA additive up to $50 \mathrm{wt} \%$ increased the charge passed of the SFC-SSC concrete because of the less condensed microstructures of specimens. On the other hand, the charge passed through the OPC concrete fell in the range of moderate chloride ion penetrability, which was associated with the low durability in term of chloride penetration resistance.

\section{Conclusion}

The new way to formulate the low energy super-sulfated cement by using low calcium Class F fly ash (FFA) has been proposed to produce self-compacting concrete with improved engineering properties and lowered cost of concrete manufacture. The 28-day compressive strengths of the SFC-SSC concrete were in the range of 41.8 65.6 MPa with FFA additive up to $50 \mathrm{wt}$ \%. In this study, FFA additive up to $50 \mathrm{wt}$ \% is shown to be adequately

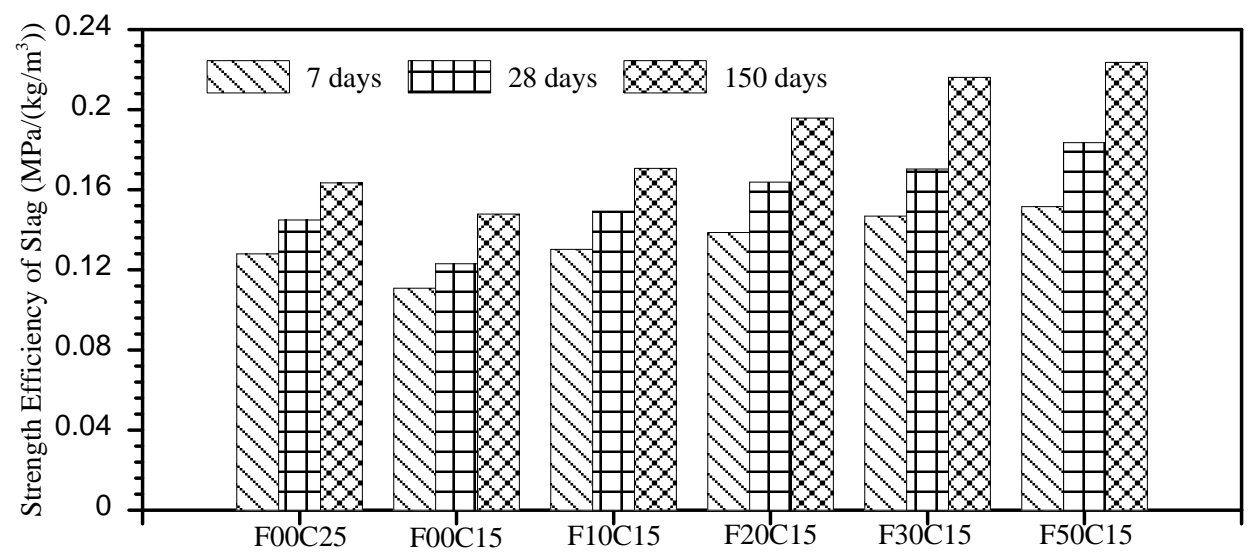

Figure 4. Strength efficiencies (SE) of slag in the SFC-SSC concrete.

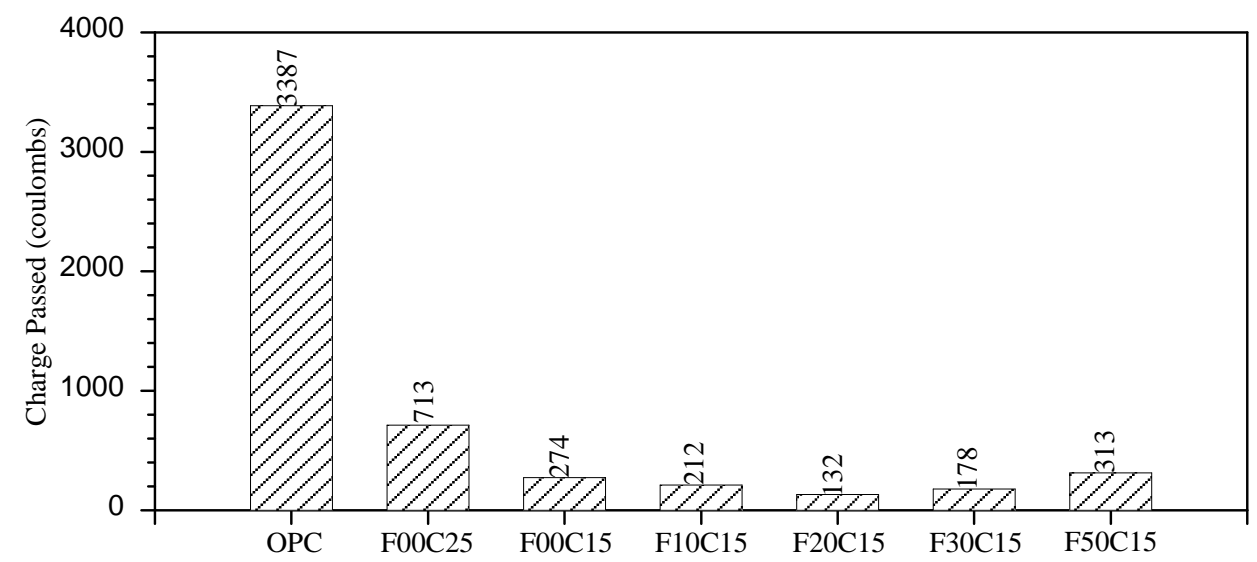

Figure 5. Charge passed of SFC-SSC concrete at age of 28 days with different mix proportions. 
used for the sustainable development due to the low cost, high durability, and most acceptable engineering properties of the resulting SFC-SSC concrete.

\section{Acknowledgements}

The authors would like to acknowledge the financial aid from the National Taiwan University of Science and Technology (NTUST) (Taiwan Tech) and the Ministry of Science and Technology, Taiwan, through research grant of 103-2221-E-011-078 -MY3 for this investigation.

\section{References}

[1] Juenger, M.C.G., Winnefeld, F., Provis, J.L. and Ideker, J.H. (2011) Advances in Alternative Cementitious Binders. Cement and Concrete Research, 41, 1232-1243. http://dx.doi.org/10.1016/j.cemconres.2010.11.012

[2] Dutta, D.K. and Borthakur, P.C. (1990) Activation of Low Lime High Alumina Granulated Blast Furnace Slag by Anhydrite. Cement and Concrete Research, 20, 711-722. http://dx.doi.org/10.1016/0008-8846(90)90005-I

[3] Gruskovnjak, A., Lothenbach, B., Winnefeld, F., Figi, R., Ko, S.C., Adler, M., et al. (2008) Hydration Mechanisms of Super Sulphated Slag Cement. Cement and Concrete Research, 38, 983-992. http://dx.doi.org/10.1016/j.cemconres.2008.03.004

[4] Midgley, H.G. and Pettifer, K. (1971) The Micro Structure of Hydrated Super Sulphated Cement. Cement and Concrete Research, 1, 101-104. http://dx.doi.org/10.1016/0008-8846(71)90086-X

[5] Singh, M. and Garg, M. (2002) Calcium Sulfate Hemihydrate Activated Low Heat Sulfate Resistant Cement. Construction and Building Materials, 16, 181-186. http://dx.doi.org/10.1016/S0950-0618(01)00026-5

[6] Bijen, J. (1996) Benefits of Slag and Fly Ash. Construction and Building Materials, 10, 309-314. http://dx.doi.org/10.1016/0950-0618(95)00014-3

[7] Imbabi, M.S., Carrigan, C. and McKenna, S. (2012) Trends and Developments in Green Cement and Concrete Technology. International Journal of Sustainable Built Environment, 1, 194-216. http://dx.doi.org/10.1016/j.ijsbe.2013.05.001

[8] Dung, N.T., Chang, T.-P. and Chen, C.-T. (2014) Engineering and Sulfate Resistance Properties of Slag-CFBC Fly Ash Paste and Mortar. Construction and Building Materials, 63, 40-48. http://dx.doi.org/10.1016/j.conbuildmat.2014.04.009

[9] Salain, I.M.A.K., Clastres, P., Bursi, J.M. and Pellissier, C. (2001) Circulating Fluidized Bed Combustion Ashes as an Activator of Ground Vitrified Blast Furnace Slag. Special Publication, 202, 225-244.

[10] Zhao, F.-Q., Ni, W., Wang, H.-J. and Liu, H.-J. (2007) Activated Fly Ash/Slag Blended Cement. Resources, Conservation and Recycling, 52, 303-313. http://dx.doi.org/10.1016/j.resconrec.2007.04.002

[11] Zhong, S., Ni, K. and Li, J. (2012) Properties of Mortars Made by Uncalcined FGD Gypsum-Fly Ash-Ground Granulated Blast Furnace Slag Composite Binder. Waste Management, 32, 1468-1472. http://dx.doi.org/10.1016/j.wasman.2012.02.014

[12] Chen, C.-T., Nguyen, H.-A., Chang, T.-P., Yang, T.-R. and Nguyen, T.-D. (2015) Performance and Microstructural Examination on Composition of Hardened Paste with No-Cement SFC Binder. Construction and Building Materials, 76, 264-272. http://dx.doi.org/10.1016/j.conbuildmat.2014.11.032

[13] Damtoft, J.S., Lukasik, J., Herfort, D., Sorrentino, D. and Gartner, E.M. (2008) Sustainable Development and Climate Change Initiatives. Cement and Concrete Research, 38, 115-127. http://dx.doi.org/10.1016/j.cemconres.2007.09.008

[14] Chen, C.-T., Nguyen, H.-A., Chang, T.-P., Yang, T.-R. and Nguyen, T.-D. (2015) Performance and Microstructural Examination on Composition of Hardened Paste with No-Cement SFC Binder. Construction and Building Materials, 76, 264-272. http://dx.doi.org/10.1016/j.conbuildmat.2014.11.032

[15] Zeng, Q., Li, K., Fen-chong, T. and Dangla, P. (2012) Determination of Cement Hydration and Pozzolanic Reaction Extents for Fly-Ash Cement Pastes. Construction and Building Materials, 27, 560-569. http://dx.doi.org/10.1016/j.conbuildmat.2011.07.007

[16] ACICommittee363. (2005) State-of-the-Art Report on High Strength Concrete. ACI 363R-92. In: ACI Manual of Concrete Practice Part I.

[17] Anthony, E.J. (1995) Fluidized Bed Combustion of Alternative Solid Fuels; Status, Successes and Problems of the Technology. Progress in Energy and Combustion Science, 21, 239-268. http://dx.doi.org/10.1016/0360-1285(95)00005-3

[18] Anthony, E.J. and Granatstein, D.L. (2001) Sulfation Phenomena in Fluidized Bed Combustion Systems. Progress in Energy and Combustion Science, 27, 215-236. http://dx.doi.org/10.1016/S0360-1285(00)00021-6 


\section{Submit or recommend next manuscript to SCIRP and we will provide best service for you:}

Accepting pre-submission inquiries through Email, Facebook, LinkedIn, Twitter, etc.

A wide selection of journals (inclusive of 9 subjects, more than 200 journals)

Providing 24-hour high-quality service

User-friendly online submission system

Fair and swift peer-review system

Efficient typesetting and proofreading procedure

Display of the result of downloads and visits, as well as the number of cited articles

Maximum dissemination of your research work

Submit your manuscript at: http://papersubmission.scirp.org/ 